\title{
The effect of BCM guided dry weight assessment on short-term survival in Chinese hemodialysis patients
}

\section{Primary results of a randomized trial - BOdy COmposition MOnitor (BOCOMO) study}

Li Liu'1,2,3,4 , Yi Sun ${ }^{5}$, Yuqing Chen ${ }^{1,2,3,4}$, Jinsheng $X u^{6}$, Ping Yuan ${ }^{7}$, Yulan Shen ${ }^{8}$, Shan Lin ${ }^{9}$, Weiming Sun ${ }^{10}$, Yingchun Ma ${ }^{11}$, Jianwei Ren ${ }^{12}$, Wenjun Liu ${ }^{13}$, Jinghong Lei ${ }^{14}$ and Li Zuo ${ }^{15^{*}}$

\begin{abstract}
Background: Lack of accurate and effective assessment tools of fluid status is one of the major challenges to reach proper dry weight (DW) in chronic hemodialysis (HD) population. The aim of this randomized study was to evaluate the effect of bioimpedance guided DW assessment on long-term outcomes in Chinese HD patients. Eligible patients were randomly assigned (1:1) to two groups in each center, the control group and body composition monitor (BCM) group. In the BCM group, DW has been evaluated by bioimpedance technic every 2 months during follow-up. The primary composite endpoint consisted of death, acute myocardial infarction, cerebral infarction, cerebral hemorrhage, and peripheral vascular disease.

Methods: A total of 445 patients were recruited from 11 hemodialysis centers from Beijing, Tianjin and Shijiazhuang cities from Jan 1, 2013 to Dec 31, 2014. They were randomized into either BCM group or control group. All patients have been followed up for 1 year or until Dec 31, 2014 or censoring.

Results: At baseline, there were no significant differences between two groups in terms of demographic parameters, dialysis vintage, percentage of vascular access, and comorbid conditions. At the end of the study, 18 (4.04\%) patients had died (11 in control group and 7 in BCM group). Kaplan-Meier survival analysis showed no significant difference in survival rates between two groups (log-rank test $P=0.07$ ). However, there was an increasing trend of survival rates in BCM group compared to the control group. In the multivariable Cox analysis, there was a nonsignificant trend toward less primary composite end points in the BCM group in the adjusted analysis, the hazard ratio was impressive $(0.487,95 \% \mathrm{Cl} 0.217-1.091, P=0.08)$.

(Continued on next page)
\end{abstract}

\footnotetext{
* Correspondence: zuoli@bjmu.edu.cn

${ }^{15}$ Department of Nephrology, Peking University People's Hospital, Beijing,

China

Full list of author information is available at the end of the article
}

(c) The Author(s). 2020 Open Access This article is licensed under a Creative Commons Attribution 4.0 International License, which permits use, sharing, adaptation, distribution and reproduction in any medium or format, as long as you give appropriate credit to the original author(s) and the source, provide a link to the Creative Commons licence, and indicate if changes were made. The images or other third party material in this article are included in the article's Creative Commons licence, unless indicated otherwise in a credit line to the material. If material is not included in the article's Creative Commons licence and your intended use is not permitted by statutory regulation or exceeds the permitted use, you will need to obtain permission directly from the copyright holder. To view a copy of this licence, visit http://creativecommons.org/licenses/by/4.0/. The Creative Commons Public Domain Dedication waiver (http://creativecommons.org/publicdomain/zero/1.0/) applies to the data made available in this article, unless otherwise stated in a credit line to the data. 
(Continued from previous page)

Conclusion: Bioimpedance technic has been applied to assess fluid status for decades and has been proved to be a promising tool for clinical practice. Although short-term outcomes were not improved in the randomized, controlled trial, the ascending trend in survival has been observed. Further studies are needed to investigate the survival benefit of bioimpedance method in DW assessment in a larger sample with longer follow-up period.

Trial registration: ClinicalTrials.org, NCT01509937. Registered 13 January 2012,

Keywords: Bioimpedance, Dry weight, Hemodialysis, Mortality, Hydration status, Body composition monitor

\section{Background}

Knowledge of optimal fluid status is essential in delivering care to maintenance hemodialysis (MHD) patients. Persistent overhydration $(\mathrm{OH})$ causes hypertension, left ventricular hypertrophy, pulmonary edema, congestive heart failure, and leads to higher mortality [1-8]. Compared with normorhydrated patients, patients with recurrent episodes of intra-dialytic hypovolemia are at a higher risk of acute ischemic events, potentially leading to functional impairment and organ damage, including accelerated loss of residual renal function [9], blood access function loss [10], brain atrophy [11], mesenteric infarction [12], and hence, higher morbidity and mortality $[13,14]$.

Optimal fluid management is critical to ensure high quality of care in patients -receiving MHD. Dry weight (DW) assessment/adjustment and control of intradialytic weight gain are main components of fluid management. However, DW assessment remains a challenge in MHD patients. Gold standard measurements of fluid status, such as isotope dilution methods, are not clinically feasible due to their complexity and great expense. Inferior vena cava diameter measurements, estimations of $\mathrm{N}$ terminal-pro-BNP (N-terminal-pro-brain natriuretic peptide) and other cardiac peptides have not been proved to be practical or reliable in the detection of fluid status in individual patients [15-17]. As a result, probing for DW based on trial and error has been common in clinical practice [18]. However, self-reported symptoms cannot be always reliable without knowing the medical history. Hypertension alone was found to be unreliable to define hypervolemia in part of some patients $[17,19]$.

Bioimpedance spectroscopy (BIS) has long been used to assess human body composition and has been extensively validated by isotope dilution methods [20, 21] and reference body composition methods [21-23]. It appears to be a promising and a valuable tool in aiding DW estimation for MHD patients. In addition, several observational studies showed the potential benefits of BIS on control of blood pressure and fluid status [1, 24]. Wizemann et al [1] found that patients who had $15 \%$ or more expansion of extra-cellular fluid (ECF) suffered higher mortality risk compared with those who had less than 15\% ECF expansion estimated by BIS method in MHD patients. Recently, Onofriescu et al. found significant improvement of survival in the bioimpedance group (aiding DW by applying BIS method) compared to the clinical methods (control) group with a follow-up of 2.5 year $(\mathrm{HR}=0.112,95 \% \mathrm{CI}, 0.014-0.918 ; P=0.04)$ in a population from Turkey [25].

This multicenter, open label, single blinded, randomized controlled trial (RCT) was designed to explore the effect of BIS guided DW assessment on long-term outcomes in Chinese patients receiving MHD.

\section{Methods}

This study design has been described previously [26]. It was approved by the Ethics Committee of Clinical Research, Peking University First Hospital and each participating center (clinical trial number: NCT01509937).

\section{Patients}

Patients were recruited from 11 clinical sites in Beijing, Tianjin and Shijiazhuang (eight centers in Beijing, two in Tianjin and 1 in Shijiazhuang) from Jan 1, 2013 to Dec 31, 2014 [26]. Beijing, Tianjin and Shijiazhuang are three main big cities located in the middle-north part of China. Patients who were older than 18 and younger than 80 years old are eligible. Patients who initiated HD less than 3 months, been dialyzed less than five times per 2 weeks, produced urine more than $800 \mathrm{ml}$ per $24 \mathrm{~h}$ the day before dialysis session, or a Kt/V less than 1.2 were excluded. Furthermore, we excluded patients with unstable clinical conditions (i.e. acute infection, heart failure), with pace-maker or metallic prosthesis (contraceptive device, artificial joint et al). Written informed consent was obtained from all patients.

\section{Study treatment}

Patients were randomized to control group and BodyComposition-Monitor (BCM) group equally in each center according to the method of random number table.

Body composition and hydration state had been assessed by a portable whole body BIS device (BCM; Fresenius Medical Care, Bad Homburg, Germany). Patient measurements were obtained before the first HD session of the week. The extracellular and intracellular fluid volumes and total body water were calculated from 
a fluid model [20]. These fluid volumes were then used to determine the fluid overload, expressed as $\mathrm{OH}$ value [27]. $\mathrm{DW}_{\mathrm{BCM}}$ was calculated by pre-weight minus $\mathrm{OH}$ $(\mathrm{kg})$.

Patients in the control group received BCM measurements at the beginning and end of the study, but the results were kept blinded to the investigators. In the control group, DW was adjusted according to the dialysis center's standard clinical practice. In the BCM group, $\mathrm{BCM}$ was performed at 2-monthly intervals during follow-up. In addition to routine practice, patients' DWs were adjusted according to BCM output data following the DW adjustment strategy.

All of baseline demographics, clinical data, laboratory data, BCM measurements, ultrasonic cardiograph data and any adverse events were monitored regularly and recorded on study case report forms according to the protocol published [26].

\section{Study outcomes}

The primary objective of the study is to compare incidence rate of the composite endpoint between $\mathrm{BCM}$ group and control group, composed of death, acute myocardial infarction, cerebral infarction, cerebral hemorrhage, and peripheral vascular disease. That had been judged by the committee of BOCOMO study comprised of all directors from every clinical site.

\section{Statistical analysis}

Normally distributed variables were expressed as mean \pm SD. Non-normally distributed variables were presented as median (25th, 75th percentiles). Categorical variables are presented as frequencies (percentages). Continuous variables were compared with the use of Student's t-test or the Mann-Whitney test (for non-normally distributed data), and categorical data with the use of chi-square tests. Survival estimates and curves were generated according to the Kaplan-Meier method. Cox regression survival analysis also was performed using a backward stepwise model adjusting for demographic data (age and gender), comorbid conditions (cardiac infarction, cerebral hemorrhage, cerebral infarction and peripheral vascular disease), and other predictors (causes of end stage renal disease (ESRD), dialysis vintage, vascular access). Both Kaplan-Meier curves and Cox model used the same end point (time to event) and patients were censored when they were transferred to another dialysis center, underwent transplantation, inserted of metallic device or were still on treatment until the end of the study. All analyses were done with SAS V9.3 (SAS Institute inc, Cary, North Carolina). A $P$ value of less than 0.05 was considered as statistically significant.

According to the data from Beijing Hemodialysis Quality Control and Improvement Center, the annual mortality rate of Beijing MHD patients is around 10\%, it is estimated that 3 year mortality to be $30 \%$. It is also estimated that the rate of composite endpoint within 3 year period of time is $40 \%$. We made an assumption that $\mathrm{BCM}$ guided DW assessment would reduce the 3-year composite endpoint rate from 40 to $32 \%$ (20\% relative risk reduction). To reach statistical significance with $\alpha<$ 0.05 and power $>80 \%$, the sample size required is 1128 . Allowing for a $20 \%$ loss-to-follow-up, the total sample size planned is 1354 . After 1 year follow-up, 6.19\% (14) of all enrolled patients (226) from 5 centers reached the composite endpoint, which was much lower than the expected rate $(13.3 \%)$. Accordingly, the sample size of the study had been recalculated and 6464 patients was required to reach the statistical significance. Given the changeable difficulty to reach that number, the followup period of the protocol was corrected to 1 year and the study had been prematurely terminated after all patients had been followed at least 1 year.

\section{Results}

A total of 445 patients were included in the final analysis (Fig. 1): $53.93 \%$ males, mean age $54.8 \pm 12.7$ years, median dialysis vintage of 4.13 years, $91.69 \%$ of them were dialyzed through an arterial venous fistula; approximately half of them had ESRD due to chronic glomerulonephritis (51.16\%) (Table 1).

Baseline characteristics of the randomly assigned patients were listed in Table 1. At baseline, there were no significant differences between two groups in terms of demographic parameters, dialysis vintage, percentage of blood access, and comorbid conditions (myocardial infarction, cerebral hemorrhage, cerebral infarction and peripheral vascular disease).

During a median follow-up of 13.7 months, 18 (4.0\%) patients died, $8(1.8 \%)$ from cerebral hemorrhage (4 in control group and 4 in BCM group, respectively), 4 (0.9\%) from infection (all in control group), $3(0.7 \%)$ from sudden death (2 in control group and 1 in BCM group), 1 (0.2\%) from heart failure (in control group), 1 (0.2\%) from respiratory failure (in BCM group) and 1 (0.2\%) from upper gastrointestinal bleeding (in BCM group) (Table 2). A total of 22 (4.9\%) patients dropped out before the study end. The reasons for censoring included transferring to other dialysis centers $(n=8,1.8 \%)$, patient refusal $(n=3,0.7 \%)$, renal transplantation $(n=3$, $0.7 \%)$, insertion of metallic joint $(n=3,0.7 \%)$ and others $(n=5,1.1 \%)$.

As mentioned in the protocol, $\mathrm{BCM}$ measurement had been done every 2 months in the BCM group. The average of $\mathrm{OH}$ values at each visit in the one-year follow-up had been shown in Fig. 2 ranged from $2.11 \mathrm{~L}$ to $2.13 \mathrm{~L}$ with a standard deviation between $1.45 \mathrm{~L}$ and $1.49 \mathrm{~L}$. 


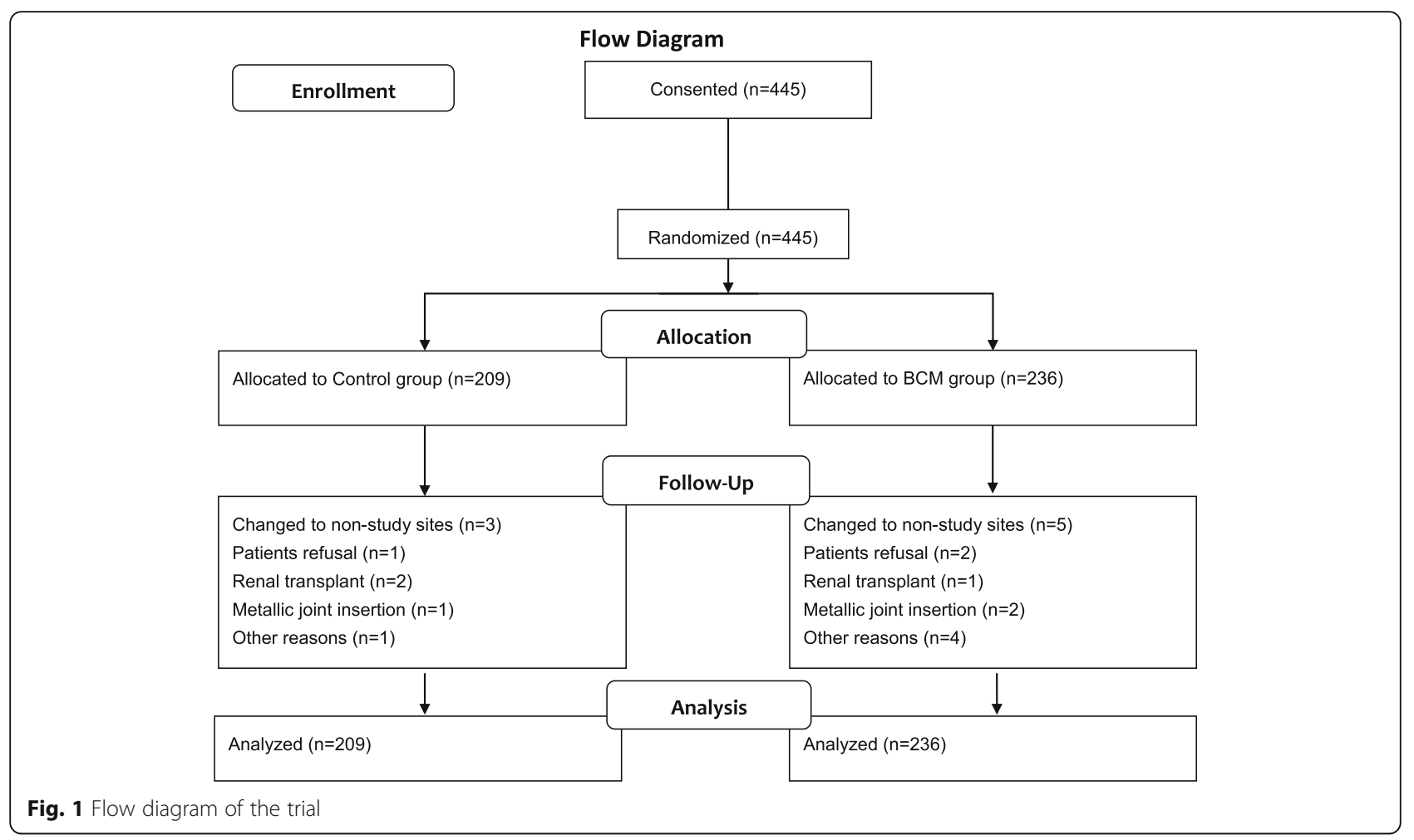

Kaplan-Meier survival analysis showed no significant difference in survival between two groups $(H R=0.51$, 95\% confidence interval: $0.24-1.08$, log-rank test $p$ value $=0.07$; Fig. 3) after 1 year follow-up. However, there was an increasing trend of survival improvement in the BCM group compared to the control group overtime.

In the multivariable Cox analysis, after adjustment for age, gender, dialysis vintage, vascular access, comorbidities and laboratory data, there was a nonsignifcant trend toward less primary composite end points in BCM group (Table 3). $(\mathrm{HR}=0.487,95 \%$ CI 0.217-1.091, $P=0.08)$.

\section{Discussion}

The present study was the first randomized control trial to investigate the survival benefit of BIS-based DW adjustment in the field of DW assessment in Chinese hemodialysis population. In this RCT study, although applying BCM to assess hydration status and adjust DW failed to improve the patients' outcome compared to the clinical standard practice in 1 year follow-up, the increasing trend of survival had been observed in the BCM group.

Bioimpedance has been applied to evaluate body composition and hydration status in both hemodialysis and peritoneal dialysis patients for decades. It is not only noninvasive and easily applicable, but also well-validated [20]. It is notable that hydration status defined by BCM was associated with survival benefits had been proved by Wizemann et al. In this study, the relation between baseline hydration status and survival in 269 hemodialysis patients [1]. It showed that overhydration defined as $15 \%$ relative to the extracellular water above the normohydration target (presented an excess of ECW of $2.5 \mathrm{~L}$ ) was linked to a more than 2-fold increased mortality risk in median follow-up of 3.5-year secondary only to the presence of diabetes.

Previous studies had demonstrated that strict BCM guided fluid management led to better blood pressure control, a decrease in arterial stiffness, a reduction of intradialytic symptoms and most importantly, a better survival [25, 28-34]. The first randomized prospective study evaluated the effect of adjustment of DW guided by $\mathrm{BCM}$ measurement every 3 months on survival was published by Onofriescu et al. from Turkey [25]. Normal hydration range was defined as $\mathrm{OH}$ value between $-1 \mathrm{~L}$ to $1 \mathrm{~L}$ in this study. It was found that all-cause mortality (both unadjusted and multivariate adjusted) was significantly lower in the bioimpedance group compared to the clinical-methods group ( $\mathrm{HR}=0.1$ and 0.112 , respectively). Although only 131 patients were enrolled, they were followed up for a long enough period (3.5 years). On the other hand, $-2 \mathrm{~L}$ to $1 \mathrm{~L}$ after dialysis was defined as the normal target of $\mathrm{OH}$ value by Chen Huan-sheng from Taiwan [33]. The incidence of acute fluid overload or cardiovascular-related events decreased significantly 
Table 1 Demographic characteristics and baseline laboratory parameters of the entire study subjects

\begin{tabular}{|c|c|c|c|c|}
\hline & All patients $(N=445)$ & Control group $(N=209)$ & BCM group $(N=236)$ & $P$-value \\
\hline Age, years & $54.8 \pm 12.7$ & $54.9 \pm 13.3$ & $54.7 \pm 12.1$ & 0.870 \\
\hline Male, N (\%) & $240(53.9)$ & 109(52.2) & $131(55.5)$ & 0.479 \\
\hline Dialysis vintage, years & $4.1(1.9,7.5)$ & $4.1(2.1,7.5)$ & $4.29(1.9,7.5)$ & 0.657 \\
\hline Follow-up, months & $13.6(12.1,15.4)$ & $13.6(12.1,15.3)$ & $13.8(12.1,15.5)$ & 0.950 \\
\hline Cause of ESRD & & & & 0.663 \\
\hline Glomerulonephritis & $220(51.2)$ & $102(50.5)$ & $118(51.8)$ & \\
\hline Diabetic kidney disease & 102(23.7) & $53(26.2)$ & $49(21.5)$ & \\
\hline Hypertension & 49(11.4) & $21(10.4)$ & $28(12.3)$ & \\
\hline Others & $59(13.7)$ & $26(12.9)$ & $33(14.5)$ & \\
\hline Vascular access & & & & 0.387 \\
\hline Arterial venous fistula & $408(91.7)$ & 193(92.3) & 215(91.1) & \\
\hline Arterial venous graft & $3(0.7)$ & $1(0.5)$ & $2(0.9)$ & \\
\hline Cuffed CVC & $26(5.8)$ & $14(6.7)$ & $12(5.1)$ & \\
\hline Temporary CVC & $3(0.7)$ & $1(0.5)$ & $2(0.9)$ & \\
\hline Directive Cannulation & $1(0.2)$ & $0(0.0)$ & $1(0.4)$ & \\
\hline Unknown & $4(0.9)$ & $0(0.0)$ & $4(1.7)$ & \\
\hline History of myocardial infarction, N (\%) & $17(3.8)$ & $7(3.4)$ & $10(4.3)$ & 0.613 \\
\hline History of cerebral hemorrhage, N (\%) & $10(2.3)$ & $4(1.9)$ & $6(2.6)$ & 0.755 \\
\hline History of cerebral infarction, N (\%) & $36(8.1)$ & $21(10.1)$ & $15(6.4)$ & 0.162 \\
\hline History of peripheral vascular disease, N (\%) & $9(2.0)$ & $6(2.9)$ & $3(1.3)$ & 0.318 \\
\hline History of percutaneous coronary intervention, N (\%) & $6(1.4)$ & $5(2.4)$ & $1(0.4)$ & 0.105 \\
\hline Hemoglobin (g/dl) & $111.5 \pm 13.7$ & $111.7 \pm 13.6$ & $111.3 \pm 13.8$ & 0.777 \\
\hline Albumin $(\mathrm{g} / \mathrm{l})$ & $40.8(38.4,43.0)$ & $41.0(38.7,43.4)$ & $40.7(38.2,42.6)$ & 0.117 \\
\hline Creatinine (umol/L) & $927.6(787.0,1071.0)$ & $916.0(792.8,1068.0)$ & $934.5(785.9,1075.0)$ & 0.653 \\
\hline $\mathrm{Kt} / \mathrm{N}$ & $1.4(1.3,1.6)$ & $1.4(1.3,1.6)$ & $1.4(1.3,1.7)$ & 0.992 \\
\hline Phosphorus (mmol/L) & $1.8 \pm 0.5$ & $1.8 \pm 0.5$ & $1.8 \pm 0.5$ & 0.970 \\
\hline iPTH (pg/ml) & $209.1(90.4,425.8)$ & $238.5(97.0,466.0)$ & 191.6(83.5, 388.6) & 0.090 \\
\hline
\end{tabular}

Data are expressed as mean $\pm S D$, median with $I Q R$, or total number with percentages, as appropriate

\#-comparison between groups

ESRD end stage renal disease, iPTH intact parathyroid hormone, CVC Central venous catheter

Table 2 list of composite primary end point by group

\begin{tabular}{|c|c|c|c|}
\hline & $\operatorname{BCM} \operatorname{group}(n=236)$ & Control group $(n=209)$ & Total(N) \\
\hline Death & 7 & 11 & 18 \\
\hline Sudden death & 1 & 2 & 3 \\
\hline Infection & 0 & 4 & 4 \\
\hline Respiratory failure & 1 & 0 & 1 \\
\hline Gastrointestinal bleeding & 1 & 0 & 1 \\
\hline Heart failure & 0 & 1 & 1 \\
\hline Cerebral hemorrhage & 4 & 4 & 8 \\
\hline Non-fatal events & 4 & 8 & 12 \\
\hline Acute myocardial infarction & 0 & 2 & 2 \\
\hline Cerebral infarction & 1 & 3 & 4 \\
\hline Cerebral hemorrhage & 2 & 1 & 3 \\
\hline Peripheral vascular disease & 1 & 2 & 3 \\
\hline
\end{tabular}




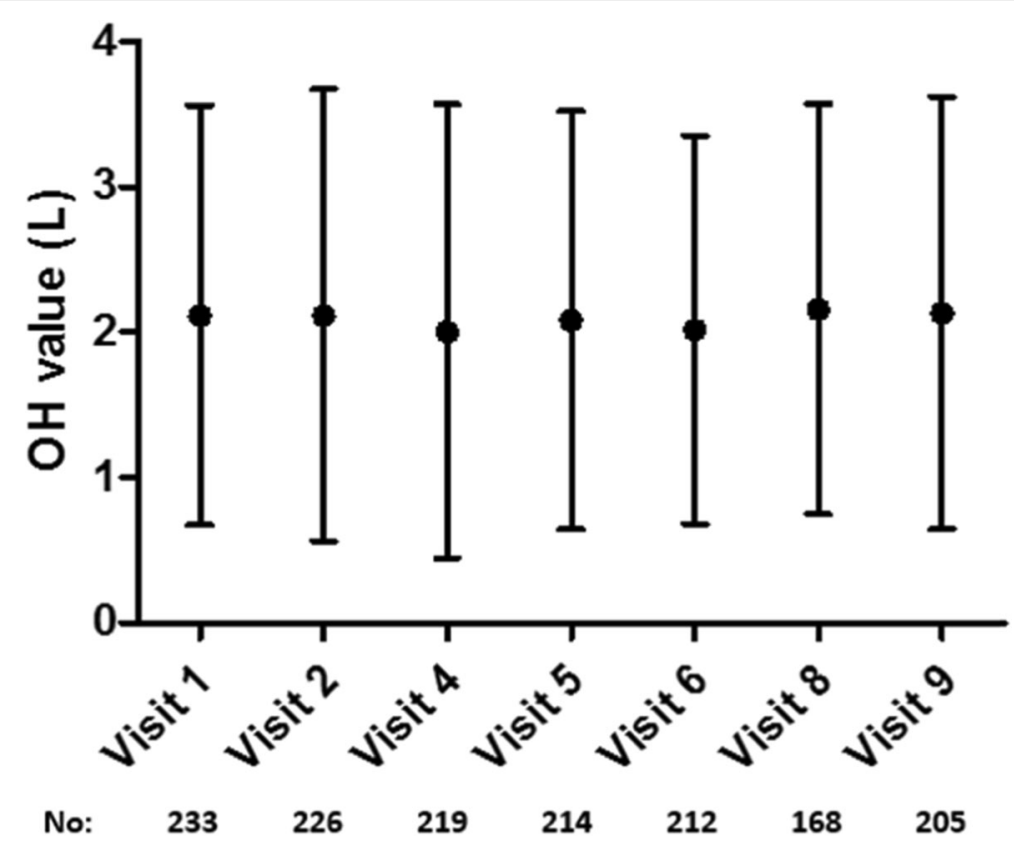

Fig. 2 The $\mathrm{OH}$ values at each visit. $\mathrm{OH}$ : overhydration

in non-diabetes mellitus patients via monthly $\mathrm{BCM}$ measurement. Compared to the above target ranges of normal hydration, we used $-1.6 \mathrm{~L}$ to $1.6 \mathrm{~L}$ in our study. After 1 year follow-up with the BCM measurement in a two-month interval, although no significant results were demonstrated, the reduction trend of overall events was observed in the BCM group. In a recent systematic review and meta-analysis which included five randomized controlled trials in HD patients [35], bioimpedancebased DW assessment was proven to be associated with

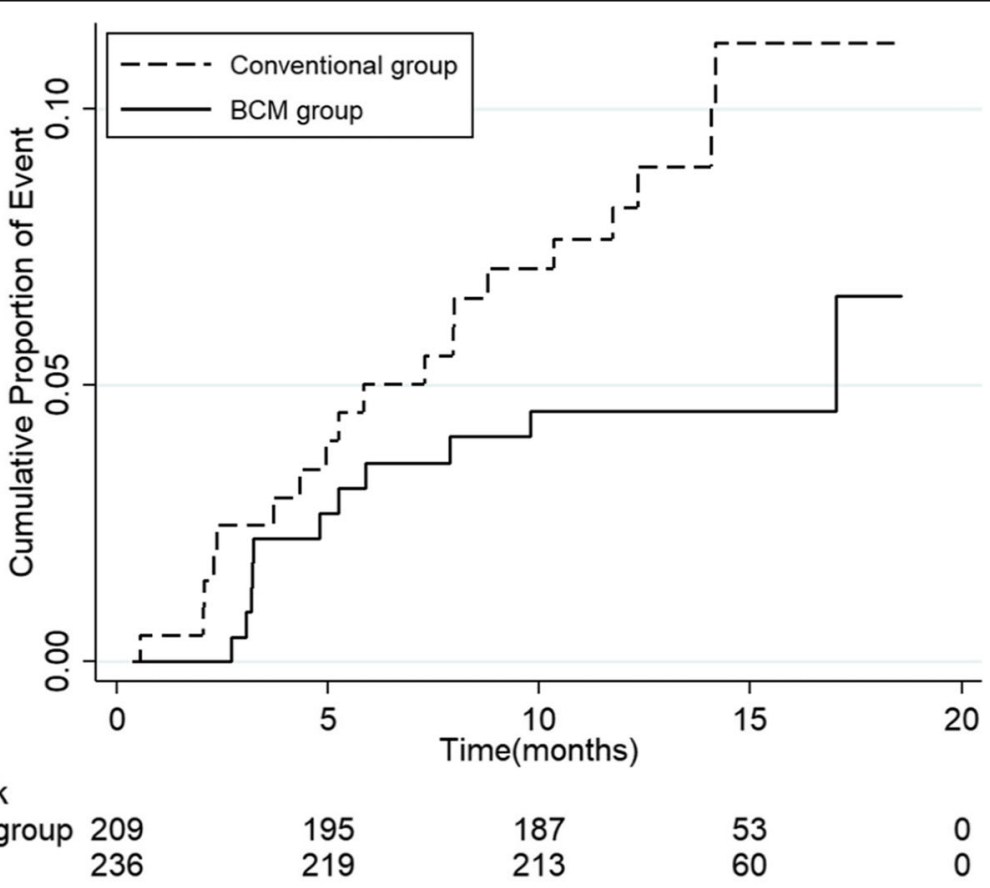

Fig. 3 Kaplan-Meier curve comparing the survival between the BCM group and Conventional group over. BCM: body-composition-monitor. (HR= $0.51,95 \%$ confidence interval: $0.24-1.08$, log-rank test $p$-value $=0.07)$ 
Table 3 Results of the multivariate Cox adjusted model

\begin{tabular}{|c|c|c|c|c|}
\hline \multirow[t]{2}{*}{ Variable } & \multirow{2}{*}{$\begin{array}{l}\text { Hazard } \\
\text { ratio }\end{array}$} & \multicolumn{2}{|l|}{$95 \% \mathrm{Cl}$} & \multirow{2}{*}{$\begin{array}{l}p \text { - } \\
\text { value }\end{array}$} \\
\hline & & Lower & Upper & \\
\hline \multicolumn{5}{|l|}{ Group } \\
\hline $\mathrm{BCM}$ group & 0.487 & 0.217 & 1.091 & 0.0804 \\
\hline Control group & \multicolumn{4}{|l|}{ Reference } \\
\hline Age & 1.02 & 0.979 & 1.062 & 0.3379 \\
\hline \multicolumn{5}{|l|}{ Gender } \\
\hline Female & 1.173 & 0.451 & 3.051 & 0.7439 \\
\hline Male & \multicolumn{4}{|l|}{ Reference } \\
\hline Dialysis vintage & 1.039 & 0.947 & 1.14 & 0.4134 \\
\hline \multicolumn{5}{|l|}{ Cause of ESRD } \\
\hline Hypertension & 0.376 & 0.044 & 3.229 & 0.3729 \\
\hline Others & 1.142 & 0.281 & 4.645 & 0.8527 \\
\hline Diabetes & 2.533 & 0.948 & 6.765 & 0.0637 \\
\hline Chronic glomerulonephritis & \multicolumn{4}{|c|}{ Reference } \\
\hline \multicolumn{5}{|l|}{ Vascular access } \\
\hline Directive Cannulation & 0 & 0 & . & 0.9968 \\
\hline Cuffed Central venous catheter & 0.246 & 0.018 & 3.301 & 0.2896 \\
\hline Temporary central venous catheter & 0 & 0 & . & 0.9951 \\
\hline Arteriovenous fistula & 0.073 & 0.007 & 0.796 & 0.0318 \\
\hline Unknown & 0 & 0 & & 0.9944 \\
\hline Arterial venous graft & \multicolumn{4}{|l|}{ Reference } \\
\hline Hemoglobin & 0.993 & 0.966 & 1.022 & 0.6527 \\
\hline $\mathrm{Kt} / \mathrm{N}$ & 0.428 & 0.059 & 3.128 & 0.4033 \\
\hline Albumin & 0.894 & 0.814 & 0.983 & 0.0202 \\
\hline Creatinine & 1 & 0.998 & 1.002 & 0.7475 \\
\hline \multicolumn{5}{|l|}{ History of myocardial infarction } \\
\hline Yes & 0.88 & 0.19 & 4.068 & 0.8699 \\
\hline No & \multicolumn{4}{|l|}{ Reference } \\
\hline \multicolumn{5}{|l|}{ History of cerebral hemorrhage } \\
\hline Yes & 1.318 & 0.167 & 10.402 & 0.7934 \\
\hline No & \multicolumn{4}{|l|}{ Reference } \\
\hline \multicolumn{5}{|l|}{ History of cerebral infarction } \\
\hline Yes & 3.182 & 1.273 & 7.956 & 0.0133 \\
\hline No & \multicolumn{4}{|l|}{ Reference } \\
\hline \multicolumn{5}{|l|}{ History of peripheral vascular disease } \\
\hline Yes & 3.082 & 0.645 & 14.725 & 0.1583 \\
\hline No & \multicolumn{4}{|l|}{ Reference } \\
\hline Phosphorus & 2.836 & 1.201 & 6.696 & 0.0174 \\
\hline iPTH & 0.999 & 0.997 & 1.001 & 0.4717 \\
\hline
\end{tabular}

ESRD end stage renal disease, iPTH intact parathyroid hormone

improvement of systolic blood pressure and of predialysis fluid overload. Unfortunately, no significant improvement in survival rate was observed. Evidence for the survival benefits of $\mathrm{BCM}$-guided intervention is still limited due to lack of prospective trials.

The major limitations of this trial are the insufficient number of participants and the limited follow-up period. In the previous statistical analysis, 1354 patients and 3 years follow-up were necessary to reach the statistical significance. At the end of the study, the actual rate of composite endpoint was $11.7 \%$, lower than the predicted rate $(13.3 \%)$. On the other hand, the rate of recruitment of each center is lower than expected, which induced the huge difficulties to recruit a total of 6464 patients into the study. The study was considered to be terminated earlier. Eventually, this study enrolled a total of 445 patients and had been closed after 1-year follow-up. The above factors might contribute to the insignificant result of our study. Meanwhile, the baseline characteristics demonstrated that our patients had relatively physical well-being which contributed to the better survival, for instance, lower $\mathrm{OH}$ value before dialysis (less than $2.5 \mathrm{~L}$ ), both hemoglobin and albumin levels in the target range $(111.5 \mathrm{~g} / \mathrm{L}$ and $40.8 \mathrm{~g} / \mathrm{L})$, more arteriovenous fistula (91.7\%) and shorter dialysis vintage (4.1 years). We are fully aware of the failure during the recruitment and follow-up of patients. Based on the survival trend shown in our pilot study, longer intervention time and enough sicker participants were both necessary to reach a positive result in the further study. Secondly, as an additional operation, both doctors and patients could not be kept blinded to BCM measurement in this study. Thirdly, although there were fewer patients dropped out than we assumed, more patients lost follow up in the BCM group than in the control group (14 vs. 8). The latter two both may cause bias of the results. Finally, the present study has been completed 5 years ago. We made great effort to recruit more units and patients during the following years. Unfortunately, short of finances and manpower were the main barriers.

\section{Conclusion}

In conclusion, failure to assess hydration status is an important barrier to achieve and maintain DW in clinical practice in hemodialysis patients. Bioimpedence method has been proved to be an accurate, simple and inexpensive tool to define the DW. Given limited evidence for the survival benefits of BCM-guided intervention, it might become the basis of appropriate fluid management and reduce cardiovascular events and death, especially in sicker patients. Further well-designed studies with enough recruitment and follow-up period are necessary.

\section{Abbreviations}

MHD: Maintenance hemodialysis; DW: Dry weight; BIS: Bioimpedance spectroscopy; ECF: Extra-cellular fluid; BCM: Body Composition Monitor; 
$\mathrm{OH}$ : Overhydration; ESRD: End stage renal disease; iPTH: Intact parathyroid hormone; CVC: Central venous catheter

\section{Acknowledgements}

This study was supported by the Fresenius Medical Care Company. We thank all the patients who participated in this trial; Jin-Wei Wang, PhD. for help with the statistical analysis.

\section{Authors' contributions}

Research idea, study design: LZ; participants enrollment, participants followup, database management: LL, YS, YC, JX, PY, YS, SL, WS, YM, JR, WL, JL; ethics and regulatory documents preparation: LL; data analysis/interpretation and statistical analysis: LZ; supervision and mentorship: YS, YC, JX, PY, YS, SL, WS, YM, JR, WL, JL, LZ. Each author contributed important intellectual content during manuscript drafting or revision and accepts accountability for the overall work by ensuring that questions pertaining to the accuracy or integrity of any portion of the work are appropriately investigated and resolved. All authors read and approved the final manuscript.

\section{Funding}

The study was supported by the Fresenius Medical Care Company. Neither Fresenius Medical Care (which markets the Body Composition Monitor) nor the sponsor had a role in study design and conduct; data management, collection, and analysis; or preparation and submission of the manuscript.

\section{Availability of data and materials}

The individual participant data that underlie the results reported in this article (including data dictionaries), after deidentification (text, tables, figures, and appendices) are available from the corresponding author on reasonable request.

\section{Ethics approval and consent to participate}

It was approved by the Ethics Committee of Clinical Research, Peking University First Hospital and each participating center (No. 2011-03). All subjects signed informed consent forms before data collection.

\section{Consent for publication}

\section{Not applicable.}

\section{Competing interests}

All the authors declare that they have no relevant financial interests in connection with the work submitted.

\section{Author details \\ ${ }^{1}$ Renal Division, Department of Medicine, Peking University First Hospital, Beijing, China. ${ }^{2}$ Institute of Nephrology, Peking University, Beijing, China. ${ }^{3}$ Key Laboratory of Renal Disease, Ministry of Health of China, Beijing, China. ${ }^{4}$ Key Laboratory of Chronic Kidney Disease Prevention and Treatment, Ministry of Education, Beijing, China. ${ }^{5}$ Department of Nephrology, Capital Medical University Fuxing Hospital, Beijing, China. ${ }^{6}$ Department of Nephrology, The Fourth Hospital of Hebei Medical University, Shijiazhuang, Hebei, China. ${ }^{7}$ Nephrotic Blood Purification Center, Tianjin Third Central Hospital, Tianjin, China. ${ }^{8}$ Department of Nephrology, Beijing Miyun County Hospital, Beijing, China. ${ }^{9}$ Department of Nephrology, General Hospital of Tianjin Medical University, Tianjin, China. ${ }^{10}$ Department of Nephrology, Beijing Shijitan Hospital, Beijing, China. ${ }^{11}$ Department of Nephrology, Beijing Boai Hospital, China Rehabilitation Research Center, Captain Medical University, Rehabilitation Medical College, Beijing, China. ${ }^{12}$ Department of Nephrology, Aviation General Hospital, Beijing, China. ${ }^{13}$ Department of Nephrology, China Academy of Chinese Medical Sciences Guang'anmen Hospital, Beijing, China. ${ }^{14}$ Department of Nephrology, Beijing Aerospace General Hospital, Beijing, China. ${ }^{15}$ Department of Nephrology, Peking University People's Hospital, Beijing, China.}

Received: 23 January 2020 Accepted: 5 April 2020

Published online: 15 April 2020

\section{References}

1. Wizemann $V$, Wabel $P$, Chamney $P$, et al. The mortality risk of overhydration in haemodialysis patients. Nephrol Dial Transplant. 2009;24(5):1574-9.
2. Zoccali C, Moissl U, Chazot C, et al. Chronic fluid overload and mortality in ESRD. J Am Soc Nephrol. 2017;28(8):2491-7.

3. Hecking M, Moissl U, Genser B, et al. Greater fluid overload and lower interdialytic weight gain are independently associated with mortality in a large international hemodialysis population. Nephrol Dial Transplant. 2018; 33(10):1832-42

4. Dekker MJ, Marcelli D, Canaud BJ, et al. Impact of fluid status and inflammation and their interaction on survival: a study in an international hemodialysis patient cohort. Kidney Int. 2017;91(5):1214-23.

5. Onofriescu M, Siriopol D, Voroneanu L, et al. Overhydration, cardiac function and survival in hemodialysis patients. PLoS One. 2015;10(8):e0135691.

6. Tabinor M, Elphick E, Dudson M, Kwok CS, Lambie M, Davies SJ. Bioimpedance-defined overhydration predicts survival in end stage kidney failure (ESKF): systematic review and subgroup meta-analysis. Sci Rep. 2018; 8(1):4441.

7. Dekker M, Konings C, Canaud B, et al. Pre-dialysis fluid status, pre-dialysis systolic blood pressure and outcome in prevalent haemodialysis patients: results of an international cohort study on behalf of the MONDO initiative. Nephrol Dial Transplant. 2018;33(11):2027-34.

8. Siriopol D, Siriopol M, Stuard S, et al. An analysis of the impact of fluid overload and fluid depletion for all-cause and cardiovascular mortality. Nephrol Dial Transplant. 2019;34(8):1385-93.

9. Jansen MA, Hart AA, Korevaar JC, et al. Predictors of the rate of decline of residual renal function in incident dialysis patients. Kidney Int. 2002;62(3): 1046-53.

10. Puskar D, Pasini J. Savić, Bedalov G, Sonicki Z. survival of primary arteriovenous fistula in 463 patients on chronic hemodialysis. Croat Med J. 2002;43(3):306-11.

11. Mizumasa T, Hirakata H, Yoshimitsu T, et al. Dialysis-related hypotension as a cause of progressive frontal lobe atrophy in chronic hemodialysis patients: a 3-year prospective study. Nephron Clin Pract. 2004;97(1):c23-30.

12. John AS, Tuerff SD, Kerstein MD. Nonocclusive mesenteric infarction in hemodialysis patients. J Am Coll Surg. 2000;190(1):84-8.

13. Shoji T, Tsubakihara Y, Fujii M, Imai E. Hemodialysis-associated hypotension as an independent risk factor for two-year mortality in hemodialysis patients. Kidney Int. 2004;66(3):1212-20.

14. Tislér A, Akócsi K, Hárshegyi I, et al. Comparison of dialysis and clinical characteristics of patients with frequent and occasional hemodialysisassociated hypotension. Kidney Blood Press Res. 2002;25(2):97-102.

15. Cheriex EC, Leunissen KM, Janssen JH, Mooy JM, van Hooff JP. Echography of the inferior vena cava is a simple and reliable tool for estimation of 'dry weight' in haemodialysis patients. Nephrol Dial Transplant. 1989;4(6):563-8.

16. Lee SW, Song JH, Kim GA, Lim HJ, Kim MJ. Plasma brain natriuretic peptide concentration on assessment of hydration status in hemodialysis patient. Am J Kidney Dis. 2003;41(6):1257-66.

17. Vasko R, Müller GA, Ratliff BB, Jung K, Gauczinski S, Koziolek MJ. Clinical judgment is the most important element in overhydration assessment of chronic hemodialysis patients. Clin Exp Nephrol. 2013;17(4):563-8.

18. Canaud B, Lertdumrongluk P. Probing 'dry weight' in haemodialysis patients: 'back to the future'. Nephrol Dial Transplant. 2012;27(6):2140-3.

19. Wabel P, Moissl U, Chamney P, et al. Towards improved cardiovascular management: the necessity of combining blood pressure and fluid overload. Nephrol Dial Transplant. 2008;23(9):2965-71.

20. Moissl UM, Wabel P, Chamney PW, et al. Body fluid volume determination via body composition spectroscopy in health and disease. Physiol Meas. 2006;27(9):921-33.

21. van den Ham EC, Kooman JP, Christiaans $\mathrm{MH}$, et al. Body composition in renal transplant patients: bioimpedance analysis compared to isotope dilution, dual energy X-ray absorptiometry, and anthropometry. J Am Soc Nephrol. 1999;10(5):1067-79.

22. McClanahan BS, Stockton MB, Lanctot JQ, et al. Measurement of body composition in 8-10-year-old African-American girls: a comparison of dualenergy $\mathrm{X}$-ray absorptiometry and foot-to-foot bioimpedance methods. Int J Pediatr Obes. 2009:4(4):389-96.

23. Lintsi M, Kaarma H, Kull I. Comparison of hand-to-hand bioimpedance and anthropometry equations versus dual-energy $\mathrm{X}$-ray absorptiometry for the assessment of body fat percentage in 17-18-year-old conscripts. Clin Physiol Funct Imaging. 2004;24(2):85-90.

24. Pillon L, Piccoli A, Lowrie EG, Lazarus JM, Chertow GM. Vector length as a proxy for the adequacy of ultrafiltration in hemodialysis. Kidney Int. 2004; 66(3):1266-71. 
25. Onofriescu M, Hogas S, Voroneanu L, et al. Bioimpedance-guided fluid management in maintenance hemodialysis: a pilot randomized controlled trial. Am J Kidney Dis. 2014;64(1):111-8.

26. Liu L, Long G, Ren J, et al. A randomized controlled trial of long term effect of BCM guided fluid management in MHD patients (BOCOMO study): rationales and study design. BMC Nephrol. 2012;13:120.

27. Chamney PW, Wabel P, Moissl UM, et al. A whole-body model to distinguish excess fluid from the hydration of major body tissues. Am J Clin Nutr. 2007:85(1):80-9.

28. Machek P, Jirka T, Moissl U, Chamney P, Wabel P. Guided optimization of fluid status in haemodialysis patients. Nephrol Dial Transplant. 2010;25(2): 538-44

29. Moissl U, Arias-Guillen M, Wabel P, et al. Bioimpedance-guided fluid management in hemodialysis patients. Clin J Am Soc Nephrol. 2013;8(9): 1575-82.

30. Hur E, Usta M, Toz H, et al. Effect of fluid management guided by bioimpedance spectroscopy on cardiovascular parameters in hemodialysis patients: a randomized controlled trial. Am J Kidney Dis. 2013;61(6):957-65

31. Vujicic B, Mikolasevic I, Racki S, Orlic L, Ljutic D, Bubic I. BCM--body composition monitor: a new tool for the assessment of volume-dependent hypertension in patients on maintenance haemodialysis. Coll Antropol. 2013:37(3):815-9.

32. Onofriescu M, Mardare NG, Segall $L$, et al. Randomized trial of bioelectrical impedance analysis versus clinical criteria for guiding ultrafiltration in hemodialysis patients: effects on blood pressure, hydration status, and arterial stiffness. Int Urol Nephrol. 2012:44(2):583-91.

33. Huan-Sheng C, Yeong-Chang C, Ming-Hsing H, et al. Application of bioimpedance spectroscopy in Asian dialysis patients (ABISAD-III): a randomized controlled trial for clinical outcomes. Int Urol Nephrol. 2016; 48(11):1897-909.

34. Patel HV, Annigeri RA, Kowdle PC, et al. Bioimpedance spectroscopy-guided ultrafiltration normalizes hydration and reduces Intradialytic adverse events in hemodialysis patients. Indian J Nephrol. 2019;29(1):1-7.

35. Covic A, Ciumanghel Al, Siriopol D, et al. Value of bioimpedance analysis estimated "dry weight" in maintenance dialysis patients: a systematic review and meta-analysis. Int Urol Nephrol. 2017;49(12):2231-45.

\section{Publisher's Note}

Springer Nature remains neutral with regard to jurisdictional claims in published maps and institutional affiliations.

Ready to submit your research? Choose BMC and benefit from:

- fast, convenient online submission

- thorough peer review by experienced researchers in your field

- rapid publication on acceptance

- support for research data, including large and complex data types

- gold Open Access which fosters wider collaboration and increased citations

- maximum visibility for your research: over $100 \mathrm{M}$ website views per year

At $\mathrm{BMC}$, research is always in progress.

Learn more biomedcentral.com/submissions 